\title{
Erratum to: Complex Networks and Link Streams for the Empirical Analysis of Large Software
}

\author{
Matthieu Latapy ${ }^{1,2}$ and Tiphaine Viard ${ }^{1,2}$ \\ ${ }^{1}$ Sorbonne Universités, UPMC Univ Paris 06, UMR 7606, LIP6, Paris, France \\ ${ }^{2}$ CNRS, UMR 7606, LIP6, Paris, France \\ FirstName. LastNamedip6.fr
}

\section{Erratum to:}

\section{Chapter 3 in: Gianfranco Ciardo Ekkart Kindler (Eds.) Application and Theory of Petri Nets and Concurrency, DOI: 10.1007/978-3-319-07734-5_3}

The author list of this paper has been updated due to a name change.

\footnotetext{
The updated original online version for this chapter can be found at 10.1007/978-3-319-07734-5_3 